\title{
Small-Molecule Protein Tyrosine Phosphatase Inhibition as a Neuroprotective Treatment after Spinal Cord Injury in Adult Rats
}

\author{
Shojiro Nakashima, ${ }^{1,4}$ Sheila A. Arnold, ${ }^{2,4}$ Edward T. Mahoney, ${ }^{1,4}$ Srinivas D. Sithu, ${ }^{3,4}$ Y. Ping Zhang, ${ }^{1,4}$ \\ Stanley E. D'Souza, ${ }^{3,4}$ Christopher B. Shields, ${ }^{1,4}$ and Theo Hagg ${ }^{1,2,4}$ \\ Departments of ${ }^{1}$ Neurological Surgery, ${ }^{2}$ Pharmacology and Toxicology, and ${ }^{3}$ Physiology and Biophysics, and ${ }^{4}$ Kentucky Spinal Cord Injury Research Center, \\ University of Louisville, Louisville, Kentucky 40292
}

\begin{abstract}
Spinal cord injury causes progressive secondary tissue degeneration, leaving many injured people with neurological disabilities. There are no satisfactory neuroprotective treatments. Protein tyrosine phosphatases inactivate neurotrophic factor receptors and downstream intracellular signaling molecules. Thus, we tested whether the peroxovanadium compound potassium bisperoxo $(1,10$ phenanthroline)oxovanadate $(\mathrm{V})[\mathrm{bpV}(\mathrm{phen})]$, a stable, potent and selective protein tyrosine phosphatase inhibitor, would be neuroprotective after a thoracic spinal cord contusion in adult rats. Intrathecal $\mathrm{bpV}$ (phen) infusions through a lumbar puncture rescued dorsal column sensory axons innervating the nucleus gracilis and white matter at the injury epicenter. At the most effective dose, essentially all of these axons and most of the white matter at the epicenter were spared (vs $\sim 60 \%$ with control infusions). bpV(phen) treatments started $4 \mathrm{~h}$ after contusion were fully effective. This treatment greatly improved and normalized sensorimotor function in a grid-walking test and provided complete axonal protection over 6 weeks. The treatment rescued sensory-evoked potentials that disappeared after dorsal column transection. $\mathrm{bpV}$ (phen) affected early degenerative mechanisms, because the main effects were seen at $7 \mathrm{~d}$ and lasted beyond the treatment period. The neuroprotection appeared to be mediated by rescue of blood vessels. bpV(phen) reduced apoptosis of cultured endothelial cells. These results show that a small molecule, used in a clinically relevant manner, reduces loss of long-projecting axons, myelin, blood vessels, and function in a model relevant to the most common type of spinal cord injury in humans. They reveal a novel mechanism of spinal cord degeneration involving protein tyrosine phosphatases that can be targeted with therapeutic drugs.
\end{abstract}

Key words: axon; blood vessel; degeneration; myelin; neuroprotection; sensory

\section{Introduction}

Spinal cord injury causes immediate mechanical tissue damage followed by secondary degeneration over a period of weeks, leading to loss of axons, myelin, blood vessels, and tissue at the injury site (Loy et al., 2002; Casella et al., 2006; Hagg and Oudega, 2006). Many long-projecting axons are not severed by the primary injury, particularly after contusions, and protecting them and their myelin is expected to reduce the devastating loss of function. Contusions comprise $\sim 25-40 \%$ of human injuries (Liverman et al., 2005). Few studies have convincingly shown therapeutic pro-

\footnotetext{
Received Nov. 16, 2007; accepted May 20, 2008.

This work was supported by a grant from the Kentucky Spinal Cord and Head Injury Research Trust (T.H.) and National Institutes of Health Grants NS045734 (T.H.) and RR015576 (C.B.S., T.H.). Endowed Chairs (C.B.S., T.H.) were supported by Bucks for Brains, Kentucky Spinal Cord and Head Injury Research Trust, and Norton Healthcare. We thank Sheher Sun for technical assistance, Aaron Puckett for animal care, and Darlene Burke for help with grid- walk testing. We are grateful for the gift of bpV(phen) by Dr. Alan Shaver from McGill University (Montreal, Quebec, (anada). Drs. Charles Hubscher and David Magnuson are thanked for advice on behavioral tests.

Y.P.Z. and C.B.S. have financial interests in Louisville Impactor System, Inc., which produces the impactor machine used in this study to create the spinal cord injuries.

Correspondence should be addressed to Theo Hagg, Kentucky Spinal Cord Injury Research Center, 511 South Floyd Street, MDR Building Room 616, University of Louisville, Louisville, KY 40292. E-mail: theo.hagg@louisville.edu.

DOI:10.1523/JNEUROSCI.1826-08.2008

Copyright $\odot 2008$ Society for Neuroscience $\quad$ 0270-6474/08/287293-11\$15.00/0
}

tection of axons of passage after a contusion injury. Treatments with glial-derived neurotrophic factor (Iannotti et al., 2004) or the $\mathrm{Na}^{+}$channel antagonist riluzole (Schwartz and Fehlings, 2001) after the injury rescues some fiber systems as shown by retrograde tracing, but it is unclear whether that was attributable to protection or sprouting of fibers and whether they improved function. Phenytoin can spare white matter, locomotor and electrophysiological function, and neurofilament-positive axons (Hains et al., 2004) but needs to start $3 \mathrm{~d}$ before the injury to reach therapeutic levels. Anti-inflammatory treatments are neuroprotective, resulting in improved locomotor function (Popovich et al., 1999; Gris et al., 2004; Teng et al., 2004), but it is unclear whether that was attributable to sparing of long-projecting axons.

Neurotrophic factors have potent neuroprotective effects for a wide array of cell types in the nervous system. Most neurotrophic and growth factor receptors are activated after ligand binding by phosphorylation of intracellular tyrosines (Airaksinen and Saarma, 2002; Huang and Reichardt, 2003). Such receptors and their downstream intracellular signaling proteins are dephosphorylated by protein tyrosine phosphatases (PTPs), a balance that is important for normal cell functions (Johnson and Van Vactor, 2003; Paul and Lombroso, 2003; Alonso et al., 2004). It stands to reason that, if PTPs are inhibited, neuroprotective signaling 
might be maintained or enhanced. Peroxovanadiums are synthetic small-molecule PTP inhibitors that enhance tyrosine phosphorylation and signaling in several systems (Posner et al., 1994; Sekar et al., 1996; Ruff et al., 1997). We have shown that intracerebral infusions of a stable and potent peroxovanadium, potassium bisperoxo(1,10-phenanthroline)oxovanadate (V) [bpV(phen)], protects injured dopaminergic neurons of the substantia nigra and their projections to the striatum in adult rats (Lu et al., 2002; Yang et al., 2007). This PTP inhibition induces phosphorylation similarly to brain-derived neurotrophic factor and neurotrophin-4 (Yang et al., 2007).

Here, we tested whether PTP inhibition by bpV(phen) would reduce degeneration of primary afferent sensory axons that project through the dorsal column to the nucleus gracilis in the medulla and their white matter tracts after a contusive spinal cord injury in adult rats. We assessed lasting improvement in function as measured by behavioral and electrophysiological tests. We also determined whether the $\mathrm{bpV}$ (phen) treatment could be given in a clinically relevant manner, i.e., started $4 \mathrm{~h}$ after the primary injury, delivered via a lumbar puncture, given for a limited time, and lacking negative side effects such as pain. The potential role of inflammation or endothelial cell survival were also investigated.

\section{Materials and Methods}

Animals. Young adult female Sprague Dawley rats $(n=111 ; 180-200 \mathrm{~g}$; Harlan) were used. Experiments were approved by the University of Louisville Institutional Animal Care and Use Committee and conducted according to National Institutes of Health guidelines. All invasive procedures were performed under deep anesthesia with an intramuscular injection of $3.3 \mathrm{ml} / \mathrm{kg}$ mixture containing $25 \mathrm{mg} / \mathrm{ml}$ ketamine hydrochloride (Abbott Laboratories), $1.2 \mathrm{mg} / \mathrm{ml}$ acepromazine maleate (The Butler Company), and $0.25 \mathrm{mg} / \mathrm{ml}$ xylazine (The Butler Company) in $0.9 \%$ saline. Surgeries, behavioral measurements, sensory-evoked potentials (SEPs), and quantification of histological results were done by investigators blind to the treatment. Almost all experiments included at least one sham-operated rat (laminectomy at T9), and the ones with cholera toxin subunit B (CTB) labeling were combined for a total of $n=7$.

Spinal cord injury and intrathecal catheters. Polyethylene catheters were produced by stretching one end of a heated piece of polyethylene PE 60 tubing (Clay Adams, Becton Dickinson) to an outer diameter of $\sim 100$ $\mu \mathrm{m}$ over a $1 \mathrm{~cm}$ length. A bead was made on the $4 \mathrm{~mm}$ nonstretched part, which was glued to the flow moderator of an Alzet osmotic pump (Durect). The assembly was gas sterilized by ethylene oxide gas. Alzet pumps (7 d; model 1007D) were filled under sterile conditions with sterile $0.1 \mathrm{M}$ PBS or with PBS containing freshly dissolved bpV(phen) produced and NMR (nuclear magnetic resonance)-certified by Dr. A. Shaver (McGill University, Montreal, Quebec, Canada) (Posner et al., 1994). The flow moderator was inserted for all but 2-3 $\mathrm{mm}$ into the pump, and the pumps were incubated for overnight at room temperature in sterile saline. For the $28 \mathrm{~d}$ infusions, every $7 \mathrm{~d}$, new Alzet pumps were filled with fresh reagent and the previous subcutaneous pump was replaced.

Preparations for aseptic surgeries and postoperative care were performed as described previously (Baker et al., 2007). After a laminectomy at T9 vertebra level, the spinal column was stabilized in a frame with steel clamps inserted under the transverse processes. The contusion was applied with a set displacement of the spinal cord (0.2-0.6 mm depending on the experiment), using the Louisville Impactor System Apparatus (Zhang et al., 2008). In short, the apparatus uses a laser distance sensor emitting a laser beam to measure the distance between the intact dura at $\mathrm{T} 9$ and the tip of the impactor head positioned $12.5 \mathrm{~mm}$ directly above it. The intended spinal cord tissue displacement is set by adjusting the vertical position of the stage on which the rat is secured, using a micrometer dial. The 2-mm-diameter impactor head is then accelerated by pneumatic cylinder at a velocity of $1.0 \mathrm{~m} / \mathrm{s}$ over the first measured impactordura distance with the impactor-tissue contact duration preset at $200 \mathrm{~ms}$.
In one group, the catheters were introduced into the subarachnoid space through a small hole in the dura at T11, the tip was advanced to T9, and the infusion was started immediately after the contusion (Baker et al., 2007). All other infusions were made by inserting the catheter into the CSF at vertebral level L5/6, and the infusion was started immediately or $4 \mathrm{~h}$ after the contusion. We chose that delayed time point because lumbar infusions could be started within that time in most humans with spinal cord injury in developed countries, increasing the clinical relevance of this study. The catheter was sutured to the muscles, and the pump was placed in a subcutaneous pocket. Gelfoam (Pfizer) was used to seal the dura. Next, the rest of the flow moderator was inserted into the pump and the wound was closed in layers.

Function tests. Baseline values were determined a few days before the contusion. Sensorimotor function was tested by voluntary walking on a $45 \times 45$ inch grid with 1.5 inch holes. The hindlimb footfalls were called out by two investigators observing from different sides and recorded by a third. The test was completed after $90 \mathrm{~s}$ of walking was observed, and the total time was recorded. The potential development of pain was assessed by applying Semmes-Weinstein filaments to a shaved area of the trunk just rostral to the injury (at-level) and noting the filament size that induced a behavioral response (vocalization, orientation toward the stimulus with or without biting, avoidance by running away or moving out of the way, and freezing). For SEPs, the recording electrode made of silver was inserted into the midline epidural space just dorsal to the gracile nucleus, and an epidural reference electrode was placed over the olfactory bulb. These were anchored on the skull by dental cement. A ground electrode was placed subcutaneous on the back. Low electrical current (5 $\mathrm{mA}, 100 \mu$ s pulsed, $0.3 \mathrm{~Hz}$ ) was applied to the calves through a ring stimulating electrode while the rats were awake and lightly restrained with a cone-shaped bag, and SEPs were recorded as described previously (Zhang et al., 2007). On each of the test days, 20 traces from each rat were averaged to determine the amplitude of the SEP for each rat. After the SEP session on day 14 after injury, the dorsal column was stereotactically transected by using the Vibraknife (Zhang et al., 2004), to a depth of just dorsal to the corticospinal tract. One or $2 \mathrm{~d}$ later, the disappearance of the SEPs was confirmed.

Anterograde tracing and histological procedures. In most experiments, hindlimb sensory projections were traced with CTB by bilateral injections into the sciatic nerves $3 \mathrm{~d}$ before analysis as described previously (Baker et al., 2007). Here, the hindlimbs were sprayed with Chew Guard (Veterinary Products Laboratories) to prevent autophagy. At the end of the experiment, the rats were processed for histological analyses as described previously (Baker et al., 2007). In short, after transcardiac perfusion with PBS and $4 \%$ paraformaldehyde, the spinal cord and attached brain were postfixed overnight and cryoprotected in $30 \%$ sucrose before $40 \mu \mathrm{m}$ sagittal sections from the medulla and horizontally sections from the lumbar cord were collected in storage buffer in anatomical order. A 1 $\mathrm{cm}$ segment of injured thoracic spinal cord from each rat in an experiment was embedded in a block of freezing medium (Triangle Biomedical Sciences) and $2020-\mu \mathrm{m}$ transverse sections per $1 \mathrm{~mm}$ rostrocaudal distance were cut on a cryostat, thaw mounted onto charged microscope slides (catalog \#12-550-15; Thermo Fisher Scientific), and stored at $-20^{\circ} \mathrm{C}$.

Anterogradely labeled sensory fibers and terminals were visualized in every third section through both gracile nuclei by DAB-based immunostaining for CTB as described previously (Baker et al., 2007). The lumbar sections were stained to ensure that the CTB injections were successful as evidenced by traced afferents and motor neurons. To detect white matter at the T9 epicenter, the transverse sections were stained with a modified eriochrome cyanine (EC) staining protocol (Rabchevsky et al., 2001). The frozen slides were warmed up at $37^{\circ} \mathrm{C}$ for $60 \mathrm{~min}$, and freezing medium was removed. All other steps were at room temperature. The remaining freezing medium was removed by immersion in xylene, and the sections were hydrated through a graded alcohol range. Next, the slides were placed for $10 \mathrm{~min}$ into a solution consisting of $2 \mathrm{ml}$ of $10 \%$ $\mathrm{FeCl}_{3}$ and $40 \mathrm{ml}$ of $0.2 \% \mathrm{EC}$ (Sigma) in $0.5 \%$ aqueous $\mathrm{H}_{2} \mathrm{SO}_{4}$, brought to a final volume of $50 \mathrm{ml}$ with $\mathrm{ddH}_{2} \mathrm{O}$. After rinsing in $\mathrm{ddH}_{2} \mathrm{O}$ and differentiation for $30 \mathrm{~s}$ in $0.5 \%$ aqueous $\mathrm{NH}_{4} \mathrm{OH}$, the reaction was terminated by rinsing in $\mathrm{ddH}_{2} \mathrm{O}$. The sections were dehydrated and coverslipped 
with Entellan. The epicenter of maximal injury was determined by the rostrocaudal level with the least amount of spared white matter per transverse section. Adjacent sections were processed for doubleimmunofluorescent staining to detect Ibal (1:250; rabbit polyclonal antibody; catalog \#019-19741; Wako Bioproducts) and RECA1 (1:40; mouse monoclonal antibody; catalog \#MCA970; Serotec), using Alexa594-conjugated donkey anti-rabbit and Alexa488-conjugated donkey anti-mouse IgG as secondary antibodies (1:500; Invitrogen). To detect individual myelinated axons of the fasciculus gracilis, a section of the C3 spinal cord was stained with toluidine blue and prepared for semithin sectioning by embedding in Epon and cutting $2-\mu \mathrm{m}$-thick transverse sections. These were coverslipped in DPX.

Endothelial cell cultures. Human aortic endothelial cells (Lonza Walkersville) were plated at $5 \times 10^{4}$ cells per well in 24 well polystyrene plates and incubated with different concentrations of bpV(phen) for 6 or $18 \mathrm{~h}$ at $37^{\circ} \mathrm{C}$ in DMEM/Ham's F-12 (BioWhittaker) plus EGM-2 growth factor supplements [EGM-2 SingleQuots (Lonza Walkersville) containing hydrocortisone, human epidermal growth factor, FBS, vascular endothelial growth factor, human basic fibroblast growth factor, R3-IGF-1, ascorbic acid, heparin, and gentamicin/amphotericin-B] and 10-20\% fetal calf serum. To induce apoptosis, these cultures were serum deprived by adding $0,1.25,2.5$, or $5 \%$ fetal calf serum, instead of the normal $10-20 \%$. Afterward, the endothelial cells were fixed in $4 \%$ paraformaldehyde for $2 \mathrm{~h}$, the nuclei were stained with $2.5 \mu \mathrm{g} / \mathrm{ml}$ DNA dye Hoechst 33258 (bis-benzimide; Sigma) in PBS containing 0.1\% Triton X-100 for 30 min, and the cells were covered with Fluoromount-G (Southern Biotechnology) to reduce fluorescence-induced fading (Invitrogen).

Quantitative measurements and statistics. The extent of sensory innervation of the gracile nucleus was determined by measuring the CTBlabeled terminal fiber area in every third section as described previously (Baker et al., 2007). In short, images of every third section through the right and left gracile nuclei were analyzed using the density slice feature of the Scion Image software. The areas for all sections through both gracile nuclei were summed for each rat. Images of EC-stained sections were captured, and the positive areas were measured with Scion Image. The injury epicenter was defined by the greatest loss of EC staining in the transverse sections. Measurements of the area of EC, Iba1, or RECA1 staining were made in three sections (spaced $100 \mu \mathrm{m}$ ) per $1 \mathrm{~mm}$ rostrocaudal distance along the $1 \mathrm{~cm}$ spinal cord section and averaged for each distance. Measurements within the dorsal column were possible for EC and RECA1 staining. Iba1 measurements were made in the entire transverse plane of the spinal cord, because it was difficult to determine the borders between the dorsal column and dorsal horns. The number of spared myelinated axons at C3 was counted in semithin sections using a $63 \times$ oil objective in $15.7 \times 15.7 \mu \mathrm{m}$ grids placed over the middle part of each fasciculus gracilis (see Fig. $4 D-F$ ). The amplitudes of the SEPs were measured at the expected position seen between 11 and $15 \mathrm{~ms}$ after the stimulus artifact. Waves that could not be distinguished from the noise were assigned a zero amplitude. To determine the effects of $\mathrm{bpV}$ (phen) on endothelial apoptosis, the percentage of cultured endothelial cells with condensed or fragmented Hoechst-stained nuclei was determined by counting 10 fields per well using a $40 \times$ objective and yielding between 350 and 500 total nuclei.

Statistical analysis was performed with StatView (SAS Institute) and Microsoft Excel. Data was compared between groups using either ANOVA in cases of multiple groups or repeated measures or by the $t$ test. Statistical significance was determined by a $p$ value of $<0.05$. A trend was indicated by a $p$ value of $>0.05$ and $<0.1$.

\section{Results}

\section{Dorsal column sensory axon injury parameters}

To enable us to efficiently test whether drugs are neuroprotective, neutral, or detrimental, we first determined the injury severity that causes loss of two-thirds of the primary sensory dorsal column axons $7 \mathrm{~d}$ after injury (Baker and Hagg, 2005). Rats received a contusion at spinal level T9 with the new Louisville Impactor System Apparatus using displacements of 0 (sham laminectomy), $0.2,0.3,0.4$, or $0.6 \mathrm{~mm}(n=4 \mathrm{each})$ (Fig. $1 A)$. Four days later, the
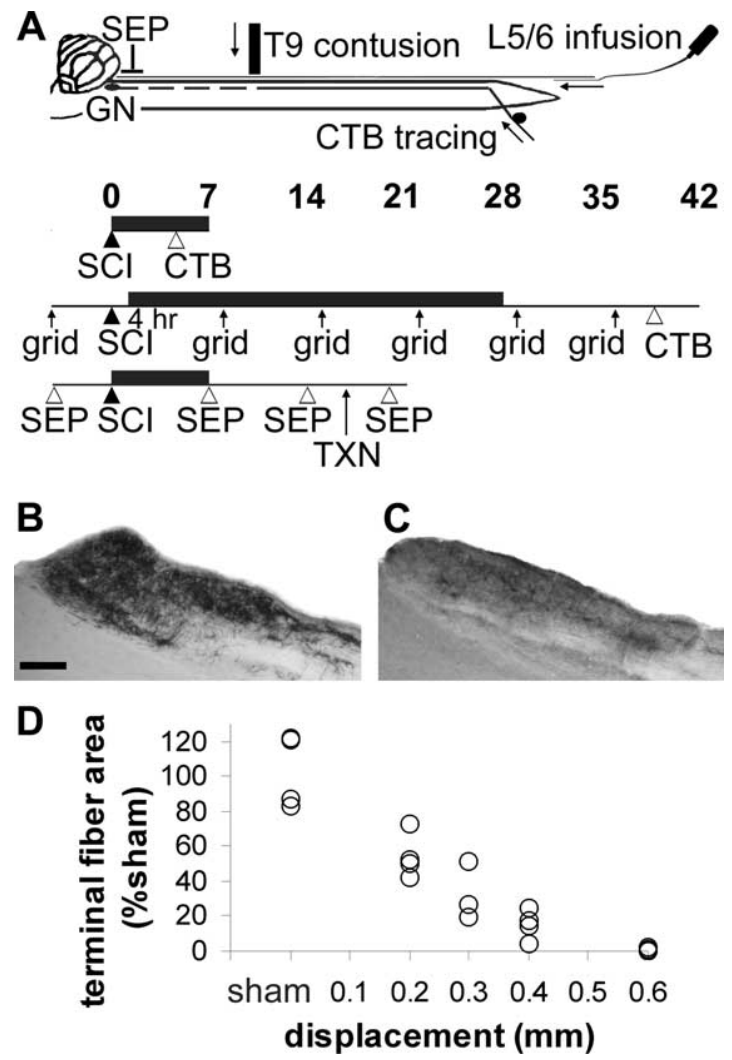

Figure 1. Model to test sensory axon protection after spinal cord contusion. $\boldsymbol{A}$, Top, The T9 contusive spinal cord injury $(\mathrm{SCl})$ results in secondary degeneration of primary sensory axons that project to the gracile nucleus (GN). Hindlimb sensory axons are anterogradely traced by injecting CTB into both sciatic nerves. Reagents are infused though a catheter placed in the CSF through an $\mathrm{L} 5 / 6$ lumbar puncture. SEPs are recorded from an epidural electrode. Experimental designs, Infusions (black horizontal bar) lasted 7 or $28 \mathrm{~d}$, and CTB was injected $3 \mathrm{~d}$ before histological processing. In one experiment, sensorimotor function was tested by grid walking (grid). In another, sensory function was tested by SEP induced from the hindlimb and confirmed by a dorsal column transection (TXN). $\boldsymbol{B}$, Normal primary sensory projections to the gracile nucleus can be visualized by CTB tracing. Scale bar, $200 \mu \mathrm{m}$. C, The projections are reduced $7 \mathrm{~d}$ after contusion. $\boldsymbol{D}$, With increasing spinal cord displacement by the impactor, more innervation is lost. The $0.3 \mathrm{~mm}$ displacement enables us to detect beneficial, detrimental, or neutral effects of test reagents.

sensory fibers and terminals were anterogradely labeled by injecting CTB into both sciatic nerves. Seven days after the injury, the sensory innervation of the gracile nucleus was reduced (Fig. 1C), with progressively fewer CTB-labeled fibers seen with increased injury displacement (Fig. 1D). Only $31 \pm 7 \%$ (percentage of sham \pm SEM) remained after a $0.3 \mathrm{~mm}$ injury, which we continued to use in most of the experiments. At the $0.6 \mathrm{~mm}$ displacement, virtually none of the projections remained present in the gracile nucleus. The variability within each group was similar to that of the sham group, suggesting that the injury severity is consistent and contributes little to the variability of the CTB-labeled projections to the gracile nucleus.

\section{Lumbar intrathecal bpV(phen) infusions protect dorsal column sensory axons and white matter}

To test the neuroprotective effects of PTP inhibition, rats with a $0.3 \mathrm{~mm}$ T9 contusion received an intrathecal (subarachnoid) infusion for $7 \mathrm{~d}$ at the T9 injury site with PBS ( $n=9$ from 2 separate experiments) or PBS with $30 \mu \mathrm{M} \mathrm{bpV}$ (phen) ( $n=9$ from 2 separate experiments). The infusion was started immediately after the injury. We have shown that this concentration can rescue 


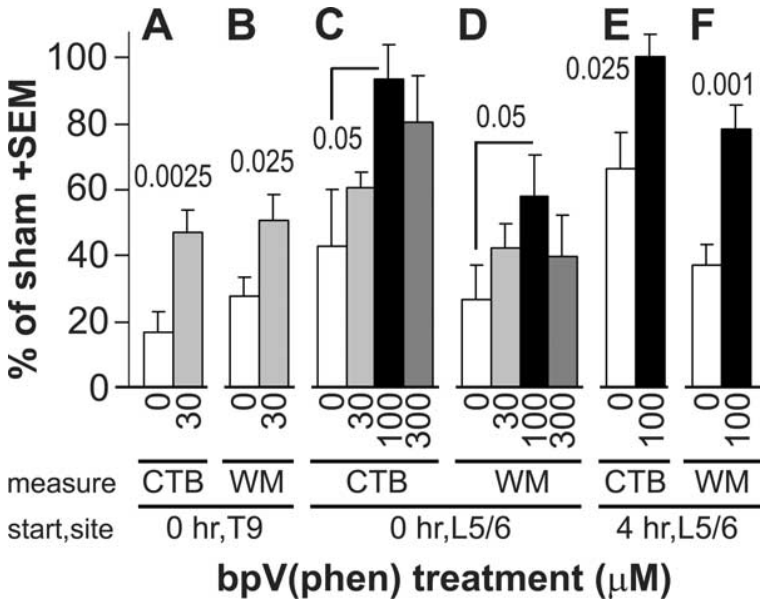

Figure 2. PTP inhibition by bpV(phen) treatment rescues dorsal column sensory axons and white matter. The concentration of $\mathrm{bpV}$ (phen), the histological measure, the time after the spinal cord contusion when the treatment was started (start), and the infusion site (site) are indicated below the graph. $A$, After a $7 \mathrm{~d}$ infusion of $30 \mu \mathrm{m} \mathrm{bpV}$ (phen) at the T9 contusion site started immediately after the injury, more sensory axons remained intact than with PBS (0), as measured by the CTB-labeled terminal fiber area in the gracile nucleus. $p$ values were less than the numbers above the bars. Values are expressed as a percentage of seven sham-operated rats. $\boldsymbol{B}, \mathrm{bpV}$ (phen) also protected the dorsal column white matter (WM) at the injury epicenter. $\boldsymbol{C}, \boldsymbol{D}$, A dose-response study using $7 \mathrm{~d}$ infusions at $L 5 / 6$ started immediately after the injury showed that $100 \mu \mathrm{m} b \mathrm{bV}$ (phen) was most effective in protecting gracile nucleus innervation (C, CTB) and T9 dorsal column white matter (D). $\boldsymbol{E}, \boldsymbol{F}$, When started $4 \mathrm{~h}$ after the contusion, $7 \mathrm{~d} \mathrm{L5/6}$ $\mathrm{bpV}$ (phen) infusions also rescued gracile nucleus innervation $(\boldsymbol{E})$ and $\mathrm{T} 9$ dorsal column white matter $(\boldsymbol{F})$

neurons after axotomy or neurotoxin lesions in Parkinson models (Lu et al., 2002; Yang et al., 2007). With bpV(phen), $47 \pm 6 \%$ (of sham) of the CTB-labeled terminal fiber area was seen in the gracile nucleus compared with $17 \pm 7 \%$ with PBS $(p<0.0025)$ (Fig. 2A). The CTB value of the PBS-infused group was not significantly different from that of the non-infused injured $0.3 \mathrm{~mm}$ displacement group. However, six of nine rats had very low values, possibly because of damage to the dorsal column axons by the dorsally positioned catheter from T11 to T9. The area of spared white matter in the dorsal column in transverse sections through the injury epicenter was also greater in the $\mathrm{bpV}$ (phen) $(50 \pm 8 \%$ of sham; $p<0.025)$ than in the PBS group $(28 \pm 6 \%)$ (Fig. $2 B$ ). This shows that local PTP inhibition by bpV(phen) infusion can reduce loss of sensory axons as well as their white matter by $7 \mathrm{~d}$ after injury.

To enhance the clinical relevance, we decided to place the infusion catheter into the CSF space at vertebral level L5/6, where there is no spinal cord. This mimics administration through a lumbar puncture in humans. To determine the lowest concentration leading to the maximum protection, rats with $0.3 \mathrm{~mm}$ T9 contusions were infused immediately after the injury with PBS $(n=4)$ or PBS containing $30 \mu \mathrm{M}(n=5), 100 \mu \mathrm{M}(n=6)$, or 300 $\mu \mathrm{M}(n=5) \mathrm{bpV}$ (phen) for $7 \mathrm{~d}$. The CTB-traced fiber area in the gracile nucleus was $43 \pm 17,60 \pm 5,93 \pm 11$ ( $p<0.05$ vs PBS), and $80 \pm 14 \%$, respectively (Fig. $2 C$ ). The value of the $100 \mu \mathrm{M}$ group was not significantly different from that of the shamoperated rats, indicating the ability of $\mathrm{bpV}$ (phen) to provide complete protection. Of note is that the PBS values were higher in the rats infused at L5/6 (Fig. 2C) than at T9 (Fig. 2A), again suggesting that the catheter can be detrimental to sensory axons after being inserted into the subarachnoid space at T11 and its tip positioned at T9. The area of spared dorsal column white matter at the injury epicenter was also greatest in the $100 \mu \mathrm{M}$ group
$(58 \pm 12 \% ; p<0.05)$ (Fig. $2 D)$. Total white matter at the epicenter was also protected in the $100 \mu \mathrm{M}$ group $(90 \pm 12$ vs $68 \pm$ $6 \%$ with PBS; $p<0.05)$. Based on these results, all following experiments used $100 \mu \mathrm{M} \mathrm{bpV}$ (phen). The epicenter white matter values in the lumbar-infused PBS group were similar to those seen in the T9-infused PBS group. This is consistent with the fact that the catheter tip was positioned just caudal to the epicenter and thus did not impinge on or cause damage to the epicenter itself.

\section{$\mathrm{bpV}$ (phen) treatment retains efficacy when started $4 \mathrm{~h}$ after spinal cord injury}

We tested whether the treatment could be delayed for $4 \mathrm{~h}$, a time period within which most diagnoses of human spinal cord injury in developed countries can be made and within which time lumbar infusions could start in most trauma centers. Rats received a $0.3 \mathrm{~mm}$ T9 contusion, and a lumbar infusion with PBS $(n=6)$ or PBS containing $100 \mu \mathrm{M} \mathrm{bpV(phen)}(n=7)$ was started $4 \mathrm{~h}$ later. Seven days later, the $\mathrm{bpV}$ (phen) group had a normal extent of gracile nucleus innervation $(100 \pm 7 \%)$, which was greater than seen with delayed PBS infusions $(66 \pm 11 \% ; p<0.025)$ (Fig. $2 E$ ) and not significantly different from the sham value. The average of the delayed PBS group was significantly greater than without infusions in the first experiment $(p<0.05)$, suggesting that the infusion per se has neuroprotective effects. The $4 \mathrm{~h}$ delayed bpV(phen) treatment also increased spared dorsal column white matter at the epicenter $(78 \pm 7$ vs $37 \pm 6 \%$ PBS; $p<0.001)$ (Fig. $2 F)$. The value of the $\mathrm{bpV}$ (phen) group was not significantly different from that of the sham group ( $p=0.53)$. Total white matter was also protected by bpV(phen) $(103 \pm 4$ vs $70 \pm 5 \%$ with PBS; $p<$ $0.00025)$.

\section{Delayed bpV(phen) treatment provides lasting improvement in sensorimotor function}

We tested whether the $4 \mathrm{~h}$ delayed treatment would have lasting neuroprotective effects, resulting in functional benefits. Therefore, rats received a $0.3 \mathrm{~mm}$ contusion at T9 and $4 \mathrm{~h}$ later were implanted with a lumbar catheter to start infusions with $\mathrm{PBS}(n=$ 9) or PBS containing $100 \mu \mathrm{M} \mathrm{bpV}$ (phen) $(n=9)$. The treatment was maintained for $28 \mathrm{~d}$ by replacing the Alzet pumps every week with ones containing fresh reagents (Fig. $1 A$ ). Weekly hindlimb grid-walking performance was used to test sensorimotor function, which is in part dependent on the primary afferents and second-order propriospinal axons of the fasciculus gracilis in the dorsal columns (Ganchrow et al., 1980; Brodal, 1992; Webb and Muir, 2003). Weekly tests showed that the bpV(phen) group performed better than the PBS group at all postinjury times $(p<$ 0.0000025 per ANOVA) (Fig. 3A). The greatest difference was seen at $8 \mathrm{~d}$, during the first postinjury test, when the number of footfalls (sum of both hindlimbs) in the bpV(phen) group (14 \pm 2 ) was half of that in the PBS group $(29 \pm 6 ; p<0.025)$ and only twice that seen before the contusion $(7 \pm 1)$. Before the contusion, when the rats were still naive (baseline values), the number of footfalls was 3-14 and was not different between the groups. At day 8 , seven of nine $\mathrm{bpV}$ (phen)-treated rats were within that normal range compared with only one of nine in the PBS group. Both groups reached plateau values by the $29 \mathrm{~d}$ test, with the $\mathrm{bpV}$ (phen) group reaching a normal average $(6 \pm 1)$ and the PBS group being significantly higher $(p<0.01 ; 13 \pm 2)$. The average of either group did not change after termination of the infusion, i.e., the 29 and $36 \mathrm{~d}$ values for each rat were not significantly different (paired $t$ test). The $\mathrm{bpV}$ (phen)-treated rats performed the required $90 \mathrm{~s}$ of grid walking quicker than the PBS-treated 

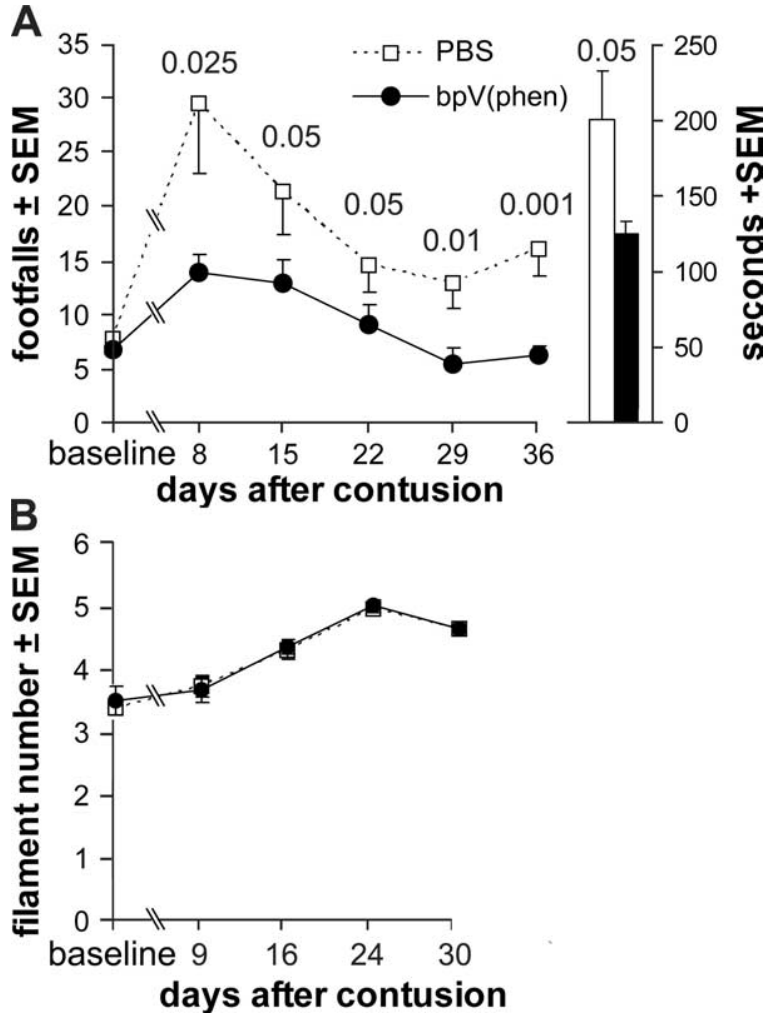

Figure 3. PTP inhibition provides lasting functional benefits after spinal cord contusion. $A$, PBS or PBS with $100 \mu \mathrm{m} \mathrm{bpV(phen)} \mathrm{was} \mathrm{infused} \mathrm{from} L 5 / 6$ for $28 \mathrm{~d}$, starting $4 \mathrm{~h}$ after a contusion at T9. Before the spinal cord contusion, the groups had similar baseline values in the grid-walk test. After the T9 spinal cord contusion, the bpV(phen)-infused group had fewer hindlimb footfalls and reached normal levels. The major effect is during the first week. The columns on the right show that peroxovandadium-treated rats completed the task quicker. $p$ values were less than the numbers over the data points. $\boldsymbol{B}, \mathrm{bpV}($ phen)-treated rats responded to the same Semmes-Weinstein filament sizes applied to the trunk as the PBS rats.

rats, with a total time of 151 vs $219 \mathrm{~s}$ at $8 \mathrm{~d}(p<0.005)$ and $125 \mathrm{vs}$ $200 \mathrm{~s}$ at $36 \mathrm{~d}(p<0.05)$ (Fig. $3 A)$. Naive rats take $\sim 150 \mathrm{~s}$ to complete the task. Thus, the bpV(phen) treatment rescued both the agility and speed at which the grid-walk test was performed, bringing them back to normal performance levels.

We tested whether $\mathrm{bpV}$ (phen) might have detrimental side effects such as inducing pain at the level of the injury. Severe spinal cord injury can induce hypersensitivity and mechanical allodynia (a painful response to a nonpainful tactile skin stimulus) at the level of injury (Hubscher and Johnson, 2006). As expected, the moderate $0.3 \mathrm{~mm}$ injury did not induce allodynia. In fact, increasingly stiffer filaments were needed to evoke a response over time after the injury, suggestive of habituation (Fig. $3 B$ ). The values of the $\mathrm{bpV}$ (phen)-infused group were not different from those of the PBS group during the entire test period. Thus, chronic bpV(phen) infusions do not induce pain, an important feature of experimental treatments that would be considered for preclinical development. We also did not observe obvious differences between any of the bpV(phen)- and PBS-treated groups in the overall health status, general behavior, and grooming of the rats (data not shown).

\section{$\mathrm{bpV}$ (phen) provides lasting protection of dorsal column sensory axons and white matter}

Four days after the last grid-walk test, the rats received injections of CTB tracer into the sciatic nerves (Fig. $1 A$ ). Three days later, i.e., $42 \mathrm{~d}$ after the injury and $14 \mathrm{~d}$ after the termination of the L5/6 intrathecal infusion, the $\mathrm{bpV}$ (phen)-treated rats had a more extensive CTB-labeled innervation of the gracile nucleus than the PBS-infused rats (Fig. $4 C$ vs $B$ ), comparable with sham rats (Fig. $4 A)$. With $\mathrm{bpV}$ (phen), the CTB value was $106 \pm 9 \%$ of sham compared with only $68 \pm 11 \%$ with PBS $[p<0.01 \mathrm{vs} \mathrm{bpV(phen);}$ $p<0.025$ vs sham] (Fig. 5A). To confirm that the axons were rescued, the middle of the fasciculus gracilis, in which the hindlimb primary afferents originating from L3-L6 are located (Smith and Bennett, 1987), was analyzed just caudal to the gracile nucleus at C3. Essentially all DRG neurons projecting to the gracile nucleus are the large ones that have myelinated axons (Cliffer and Giesler, 1989), which were counted in semithin sections. The bpV(phen)-treated rats clearly had more myelinated sensory axons (Fig. $4 F$ vs $E$ ) than the PBS-infused rats. Except for some white matter debris, the number of gracilis axons at $\mathrm{C} 3$ in the bpV(phen) group (Fig. $4 F$ ) appeared comparable with that of sham-operated rats (Fig. $4 D$ ). The number of myelinated axons was greater in the $\mathrm{bpV}$ (phen) group $(102 \pm 5 \%)$ than in the PBS group $(63 \pm 6 \%$; $p<0.0001)$ (Fig. $5 A$ ). The ratio of the CTBlabeled terminal fiber area and the $\mathrm{C} 3$ axons was the same in the $\mathrm{PBS}$ and $\mathrm{bpV}$ (phen) groups, evidence that bpV(phen) did not induce sprouting. This supports the interpretation that the bpV(phen) infusion at L4 rescued the ascending sensory axons at the T9 injury site. The area of spared white matter in the dorsal column at the T9 injury epicenter was greater in the $\mathrm{bpV}$ (phen) group $(79 \pm 7 \% ; p<0.01)$ than in the PBS group $(48 \pm 8 \%)$ (Figs. $4 I$ vs $H, 5 A$ ), indicating that $\mathrm{bpV}$ (phen) can also permanently rescue myelin. When the treatment groups were combined, regression analyses of the hindlimb grid-walk performance against the histological parameters showed the clearest correlation with the number of axons in the fasciculus gracilis at C3 (Fig. 5B). The CTB-labeled gracile nucleus innervation and area of dorsal column white matter at the T9 injury epicenter also correlated inversely with the number of footfalls $(p<0.05$ and $p<0.005$, respectively; data not shown). This further supports the interpretation that improved sensory axon and dorsal column white matter sparing contributed to improved sensorimotor function.

\section{$\mathrm{bpV}$ (phen) treatment rescues sensory-evoked potentials}

To directly test the function of the primary sensory afferents projecting to the gracile nucleus, we used SEPs, stimulating from the hindlimb and recording over the medulla (Fig. $1 A$ ). In preliminary experiments, SEPs did not disappear consistently after the $0.3 \mathrm{~mm}$ injury. Therefore, rats received a $0.4 \mathrm{~mm}$ T9 contusion and a $7 \mathrm{~d}$ lumbar infusion with PBS $(n=5)$ or PBS containing $100 \mu \mathrm{M} \mathrm{bpV}$ (phen) $(n=5)$ starting immediately after the injury. The recording electrodes had been placed and the existence of an SEP confirmed for each rat a few days before the contusion, with comparable average amplitudes of 61, 67, and 56 $\mu \mathrm{V}$ in the PBS, bpV(phen), and sham groups, respectively (Fig. $6)$. One week after the contusion, only one of five rats in the PBS group had an SEP (average, $6 \pm 6 \mu \mathrm{V}$ ) above the background noise, whereas four of five rats in the $\mathrm{bpV}$ (phen) group had an SEP (average, $21 \pm 7 \mu \mathrm{V}$ ), similar to the sham rat $(16 \mu \mathrm{V})$. One additional week after termination of the infusion, only the same rat in the PBS group had a detectable SEP (group average, $2 \pm 2$ $\mu \mathrm{V}$ ), whereas all rats in the $\mathrm{bpV}$ (phen) group had an SEP (average, $30 \pm 18$ vs $36 \mu \mathrm{V}$ of the sham rat). To confirm that the rescued SEPs were mediated by the fasciculus gracilis, the latter was transected $1 \mathrm{~mm}$ caudal to the T9 contusion site. Two days later, none of the rats had SEPs. The lesion depth was confirmed in sagittal sections. Because of the dorsal column transection, 

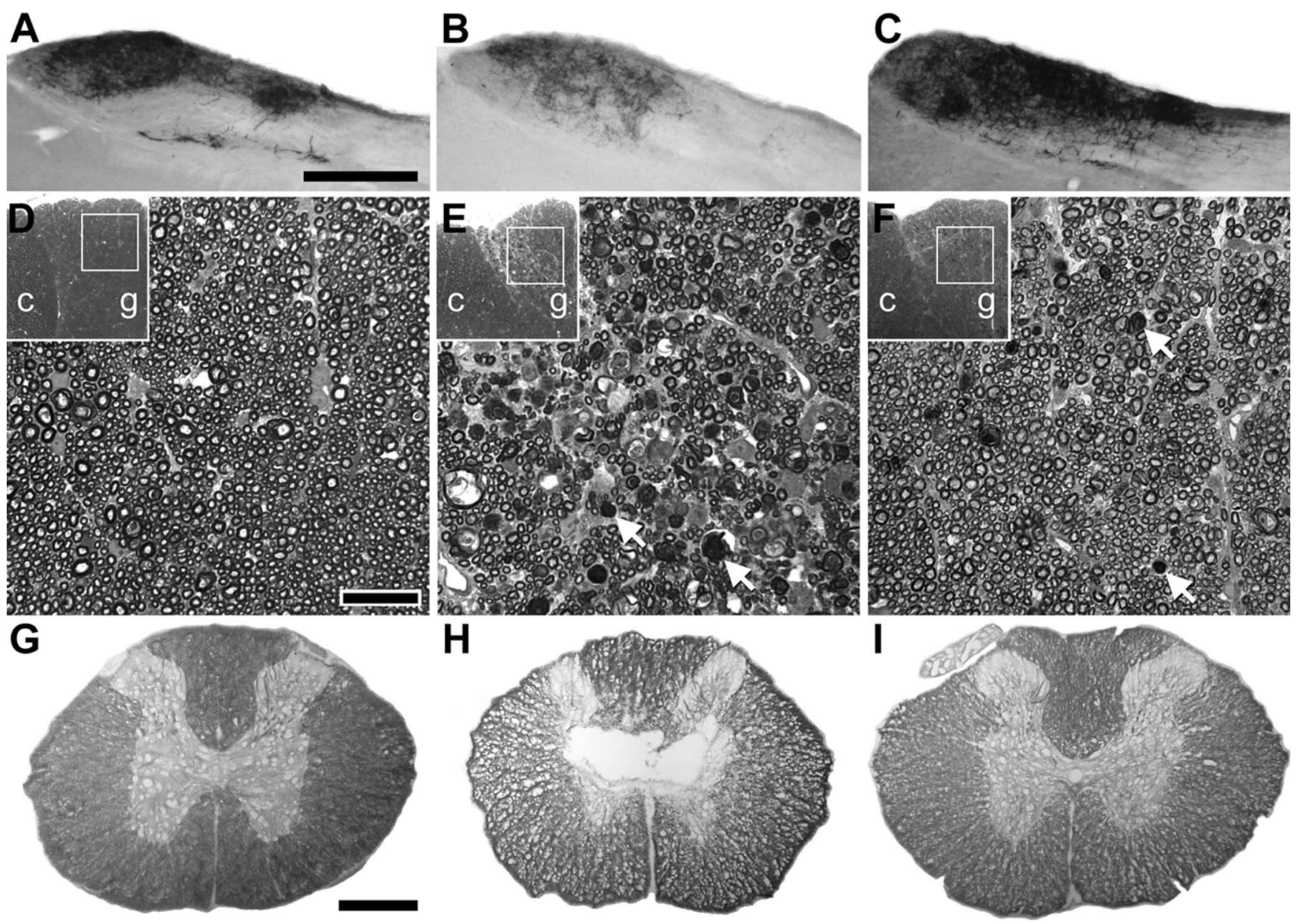

Figure 4. PTP inhibition provides lasting protection of dorsal column sensory axons and white matter after a spinal cord contusion. The rats infused for $28 \mathrm{~d}$ starting $4 \mathrm{~h}$ after contusion (Fig. 3 ) were analyzed 2 weeks later. $\boldsymbol{A}, \boldsymbol{B}$, Compared with sham-operated rats $(\boldsymbol{A})$, injured ones infused with PBS $(\boldsymbol{B})$ showed a reduction in CTB-traced innervation from the hindlimb to the gracile nucleus. C, bpV(phen)-infused rats had an apparently normal innervation (compare also with Fig. $1 B$ ). Scale bar, $500 \mu$ m. $\boldsymbol{D}, \boldsymbol{E}$, The number of myelinated axons in the fasciculus gracilis (g) at $(3$ was reduced in PBS-infused rats $(\boldsymbol{E})$ compared with sham rats $(\boldsymbol{D})$. Arrows, Examples of myelin debris. $\boldsymbol{F}$, The bpV(phen)-treated rats had an apparently normal number of axons. C, Fasciculus cuneatus. Scale bar, $20 \mu \mathrm{m} . \mathbf{G}-\boldsymbol{I}$, Injury-induced loss of white matter at the injury epicenter (H, PBS-infused rat) was reduced after infusion of bpV(phen) $(\boldsymbol{I})$ to sham levels $(\boldsymbol{G})$. Scale bar, $500 \mu \mathrm{m}$.

these rats did not receive CTB tracing, and white matter sparing could not be assessed with confidence, also because of the sagittal plane of sectioning. Thus, L5/6 intrathecal bpV(phen) infusions rescue not only the structural integrity but also the function of the primary sensory dorsal column axons after a T9 contusion. The finding that the SEP was present after the $0.3 \mathrm{~mm}$ but not the 0.4 $\mathrm{mm}$ injury suggests that SEPs can be evoked with a minimum of somewhere between 15 and $31 \%$ of the dorsal column sensory axons (Fig. 1D).

Rescue of axons, but not white matter, appears mediated by microvascular protection

Inflammation is a major contributor to white matter loss after spinal cord injury. Therefore, to find a potential mechanism for the axon- and myelin-protective effects of $\mathrm{bpV}$ (phen), we first measured its effects on Ibal immunostaining as a marker for microglial/macrophage activation and inflammation. In the rats treated with $\mathrm{bpV}$ (phen) for $7 \mathrm{~d}$ starting $4 \mathrm{~h}$ after the injury, sections through the injury epicenter clearly showed a reduction in Ibal immunostaining (Fig. $7 A$ vs $B$ ). Whereas, PBS-infused rats had clear infiltrates of activated macrophages, those infused with $\mathrm{bpV}$ (phen) had predominantly activated microglial cells. Moreover, whereas the PBS-treated rats showed degenerative changes in the gray and white matter architecture, the tissue in the
$\mathrm{bpV}$ (phen)-treated rats appeared closer to normal. The area of Ibal-immunostained structures was significantly reduced at 1 $\mathrm{mm}$ rostral to the epicenter $(p<0.005)$, whereas there was a trend of a reduction at the epicenter $(p=0.053)$ but no difference at $1 \mathrm{~mm}$ caudal to the epicenter $(p=0.49)$ (Fig. $8 A)$. The extent of white matter loss in the dorsal column at the epicenter correlated to the extent of microglia/macrophage activation at the epicenter (Fig. $8 \mathrm{~B}$ ). The extent of inflammation $1 \mathrm{~mm}$ rostral to the injury correlated with the loss of CTB-labeled sensory projections in the gracile nucleus (Fig. $8 C$ ) but not with that seen at the epicenter $(p=0.3)$ or caudal to the lesion $(p=0.57)$. This suggests that the sensory axon sparing by $\mathrm{bpV}$ (phen) was not attributable to the reduced inflammation and that the reduction in inflammation rostral to the injury site might be an indirect result of reduced axon degeneration of the ascending projections. Conversely, we cannot exclude the possibility that $\mathrm{bpV}$ (phen) affected inflammation at other times over the $7 \mathrm{~d}$ period.

Another potential contributor to axon loss is ischemia caused by blood vessel loss. To test this possibility, the same sections were analyzed for the extent of endothelial cell/blood vessel sparing by immunostaining for RECA1. The spinal cord tissue architecture of PBS-treated rats was disturbed (Fig. $7 C$ ), whereas that of $\mathrm{bpV}$ (phen)-treated rats had an essentially normal appearance of both white and gray matter (Fig. 7D). Quantification of the 

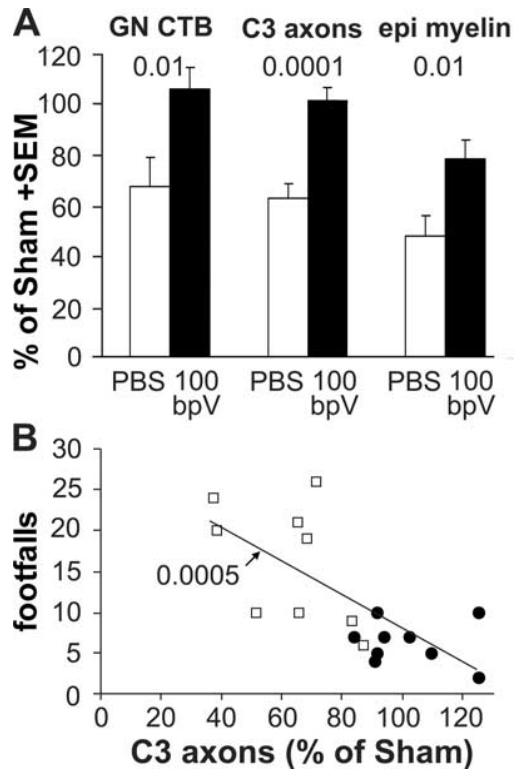

Figure 5. PTP inhibition provides lasting protection: quantification. $\boldsymbol{A}$, Six weeks after the contusion and 2 weeks after the termination of the infusion, the CTB-traced innervation of the gracile nucleus (GN CTB) was greater with infusion of $100 \mu \mathrm{m} \mathrm{bpV(phen)} \mathrm{(100} \mathrm{bpV)} \mathrm{than} \mathrm{with}$ PBS treatment and was comparable with the sham values. The number of axons in the fasciculus gracilis at $\mathrm{C} 3$ was completely protected by bpV(phen). The dorsal column white matter at the injury epicenter (epi) was protected to $\sim 80 \%$ of sham. $\boldsymbol{B}$, The number of axons at $C 3$ predicted the performance in the last grid-walk test $6 \mathrm{~d}$ before. The regression analysis was performed on data pooled from both treatment groups. The $p$ value indicates the significance of the correlation between the axon counts and the grid performance. Open squares, PBS; filled circles, $\mathrm{bpV}$ (phen).

blood vessels in the dorsal column at the epicenter showed clear loss in PBS-treated rats and sparing by bpV(phen) (Fig. 8D). The area was not significantly different between bpV(phen)-treated and sham-operated rats. Regression analyses revealed a trend between RECA1 and CTB (sensory axons; $p=0.087$ ) or dorsal column EC (myelin; $p=0.085$ ). Therefore, epicenter RECA1 was measured in additional $7 \mathrm{~d}$ postinjury groups, excluding those infused at the epicenter and those with an epicenter transection (SEP), which damaged the tissue. The bpV(phen) treatment (started immediately after the injury) increased the area of blood vessels in the dorsal column in those rats infused with 30 and 100 $\mu \mathrm{M} \mathrm{bpV}$ (phen) (Fig. 8E). A regression analysis of all the $7 \mathrm{~d}$ infused rats [PBS and all doses of bpV(phen) combined] showed a correlation between RECA1-positive blood vessels in the dorsal column at the injury epicenter and CTB-labeled sensory projections (Fig. $8 F$ ). However, there was no correlation between RECA1- and EC-stained dorsal column epicenter white matter ( $p=0.98$; data not shown). This suggests that $\mathrm{bpV}(\mathrm{phen})$ rescued the sensory axons, but not their myelin, by rescuing dorsal column blood vessels in the injury epicenter.

To determine whether $\mathrm{bpV}$ (phen) can directly promote survival of endothelial cells, we tested it on cultured human aortic endothelial cells deprived of serum. Six hours after plating, 2-3\% of the cells showed the characteristic of apoptosis, nuclear fragmentation or condensation. With $3 \mu \mathrm{m}$ bpV(phen), only $\sim 1.3 \%$ were apoptotic in both the 0 and 5\% serum groups (Fig. 9A). Eighteen hours after plating under control conditions, between 5 and $13 \%$ of endothelial cells were apoptotic, whereas treatment with $3 \mu \mathrm{M}$ bpV(phen) reduced apoptosis to $\sim 2-3 \%$ (Fig. 9B). The results from the $1 \mu \mathrm{M}$ groups suggest that suboptimal doses of $\mathrm{bpV}$ (phen) can increase the survival-promoting effects of suboptimal concentrations of serum.
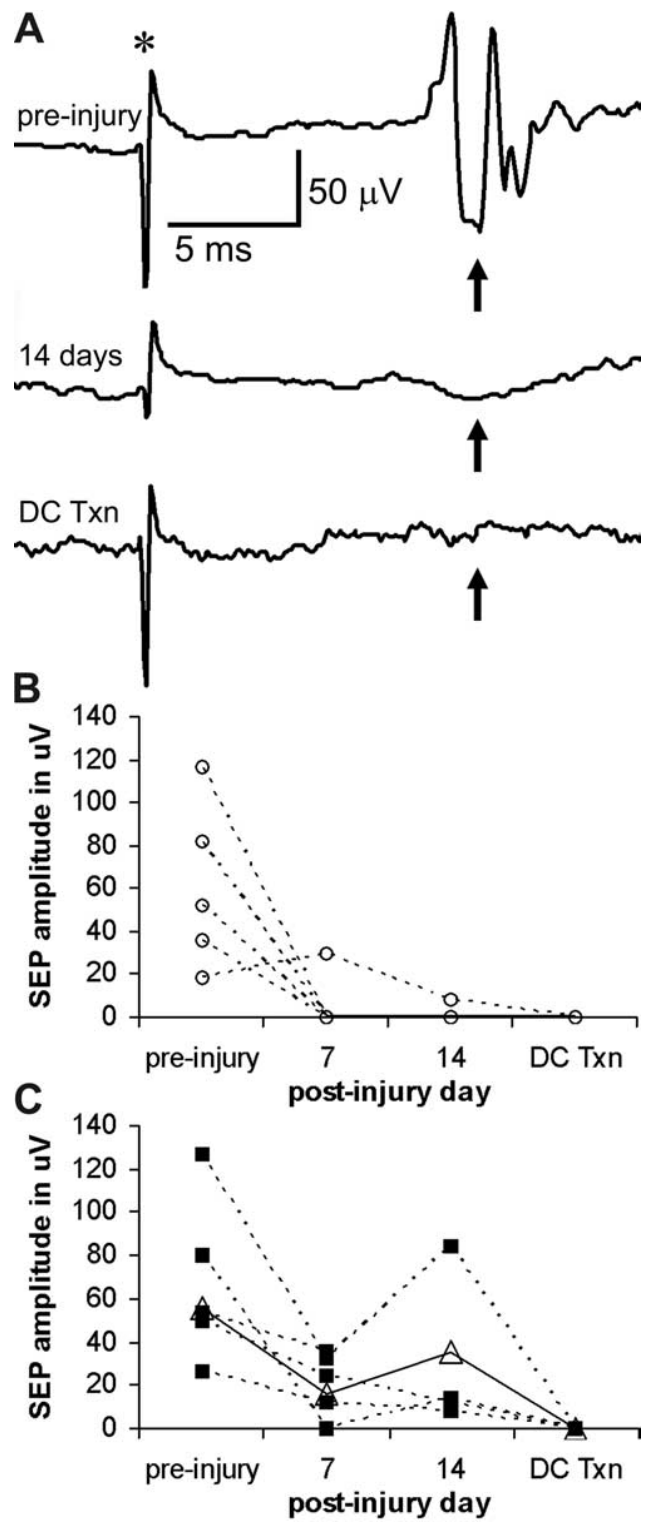

Figure 6. PTP inhibition rescues dorsal column sensory-evoked potentials after spinal cord contusion. A, An example of evoked potentials (arrows) recorded from the gracile nucleus of a rat. The SEP is evident before a spinal cord contusion, much reduced $14 \mathrm{~d}$ after injury, and absent after selective transection of the dorsal column (DC Txn) to confirm the specific role of the latter. Traces represent the average of 20 measurements. The SEP is expected between 11 and $15 \mathrm{~ms}$ after the stimulus artifact $\left(^{*}\right)$. B, SEP amplitudes of individual rats in the PBS-infused group shows the loss of SEPs after the contusion in all but one rat, as well as the disappearance of the SEP after dorsal column transection. C, All rats in the bpV(phen)-infused group had a measurable SEP after the contusion, and all SEPs disappeared after the dorsal column transection. The sham values (open triangles, solid line) are shown for comparison.

\section{Discussion}

This study provides a proof-of-principle that inhibition of PTPs can be used to reduce secondary degeneration and dysfunction of long-projecting axons, their myelin, and surrounding blood vessels, possibly identifying a novel neurodegenerative mechanism after spinal cord injury. Moreover, we show that we can apply clinically relevant treatment protocols with a small molecule to reduce the devastating outcomes of spinal cord injury.

We focused on the primary sensory system projecting from the sciatic nerve to the gracile nucleus because it is well defined and readily accessible to investigation. The hindlimb dorsal col- 
umn-medial lemniscus system is important for tactile discriminatory aspects of sensation, including spatial and temporal characteristics (Brodal, 1992; McKenna and Whishaw, 1999; Ballermann et al., 2001). In humans and monkeys, lesions to this system causes disturbance of voluntary movement, including ataxia (Brodal, 1992). Its degeneration, therefore, most likely contributes to functional sensory and motor deficits in humans with spinal cord injury. Here, the $\mathrm{bpV}$ (phen) treatment improved grid-walking performance, restoring this sensorimotor function to normal levels. The performance correlated well with the number of myelinated axons in the fasciculus gracilis, suggesting that sparing of these fibers contributed to the improved function. In rats, selective transection of the dorsal columns, excluding the dorsal corticospinal tract, cause deficits in a ladder-walking test (Ganchrow et al., 1980; Webb and Muir, 2003). However, grid walking is also dependent on propriospinal function and on ventral pathways (Schucht et al., 2002). The dorsal column at T9 also contains second-order propriospinal axons that do not project to the gracile nucleus, and the main propriospinal tract courses though the dorsolateral funiculus (Brodal, 1992).

Thus, it is possible that $\mathrm{bpV}$ (phen) also protected these and possibly other tracts. Our electrophysiological data suggest that function of the primary sensory axons was protected by the bpV(phen) treatment, because the protection disappeared after selective transection of the fasciculus gracilis just caudal to the primary injury.

These results show that primary afferent dorsal column axons can be fully protected by $\mathrm{bpV}$ (phen) treatment after a moderate spinal cord injury of $0.3 \mathrm{~mm}$ displacement. The treatment also rescued the electrophysiological conduction across the injury site to the medulla after the more severe $0.4 \mathrm{~mm}$ injury. We will need to determine whether $\mathrm{bpV}$ (phen) can protect these and other axonal systems against even more severe injuries. The protection by $\mathrm{bpV}$ (phen) seemed to add to some protection by the PBS infusion. This would be consistent with the findings that intrathecal PBS infusions increase NGF levels in the spinal cord (Bowes et al., 2000) and that NGF can reduce degeneration of stumps of directly transected dorsal column sensory axons (Sayer et al., 2002). In contrast, the infusion at the level of the injury reduced the number of spared axons in a proportion of rats, possibly related to the presence of the catheter during and/or after the primary injury. The lumbar infusions reduce such a risk as well as the risk of peripheral side effects of any drug considered for spinal cord injury and can readily be applied to humans.

The $\mathrm{bpV}$ (phen) treatment also protected white matter in the dorsal columns and the total spinal cord at the injury site. The level of dorsal column white matter protection was not complete, suggesting that full functional recovery in rats can occur in the absence of completely intact myelination and/or that recovery is also affected by the plasticity of the spinal cord caudal to the injury. Inflammation is a major contributor to white matter loss after spinal cord injury (Popovich et al., 2002). However, given the finding that $\mathrm{bpV}$ (phen) did not consistently reduce microglia/macrophage activation caudal and rostral to the injury epicenter, it is possible that the rescue of white matter by bpV(phen) indirectly reduced the inflammation. This would be consistent with the finding that the area of spared white matter inversely correlated with the Ibal area at the epicenter. The finding that the CTB-traced projections inversely correlated with the inflammatory response only rostral to the injury site suggests that the reduced degeneration of the ascending axons in $\mathrm{bpV}$ (phen)-treated rats also indirectly reduced the inflammatory response. We cannot exclude the possibility that $\mathrm{bpV}$ (phen) affected inflammation at other times over the $7 \mathrm{~d}$ period or infiltration of specific leukocytes and thereby reduced axon degeneration.

Endothelial cells die over the first day after injury (Casella et al., 2006), and sensory axons seem to undergo secondary degeneration some time after the first day (S. Nakashima and T. Hagg, unpublished observation). Therefore, we considered that the axon-protective effects of $\mathrm{bpV}$ (phen) might indirectly be attributable to protection of endothelial cells and blood vessel integrity. In fact, the sections through the spinal cord injury epicenter showed that bpV(phen)-treated rats had an almost normal blood vessel network in sharp contrast to the PBS-treated rats. Moreover, the CTB-labeled sensory projections to the gracile nucleus correlated well with the extent of blood vessel sparing. Thus, protection of blood vessels during the first postinjury week might reduce ischemia, resulting in improved axonal survival. Of note is that the white matter sparing did not correlate with sparing of the vasculature, pointing to partially different mechanisms underlying white matter and axon degeneration. Although many therapeutic agents have been shown to reduce endothelial dysfunction, few studies have reported on reduced endothelial cell death after neurotrauma and not after spinal cord injury. Activation of 

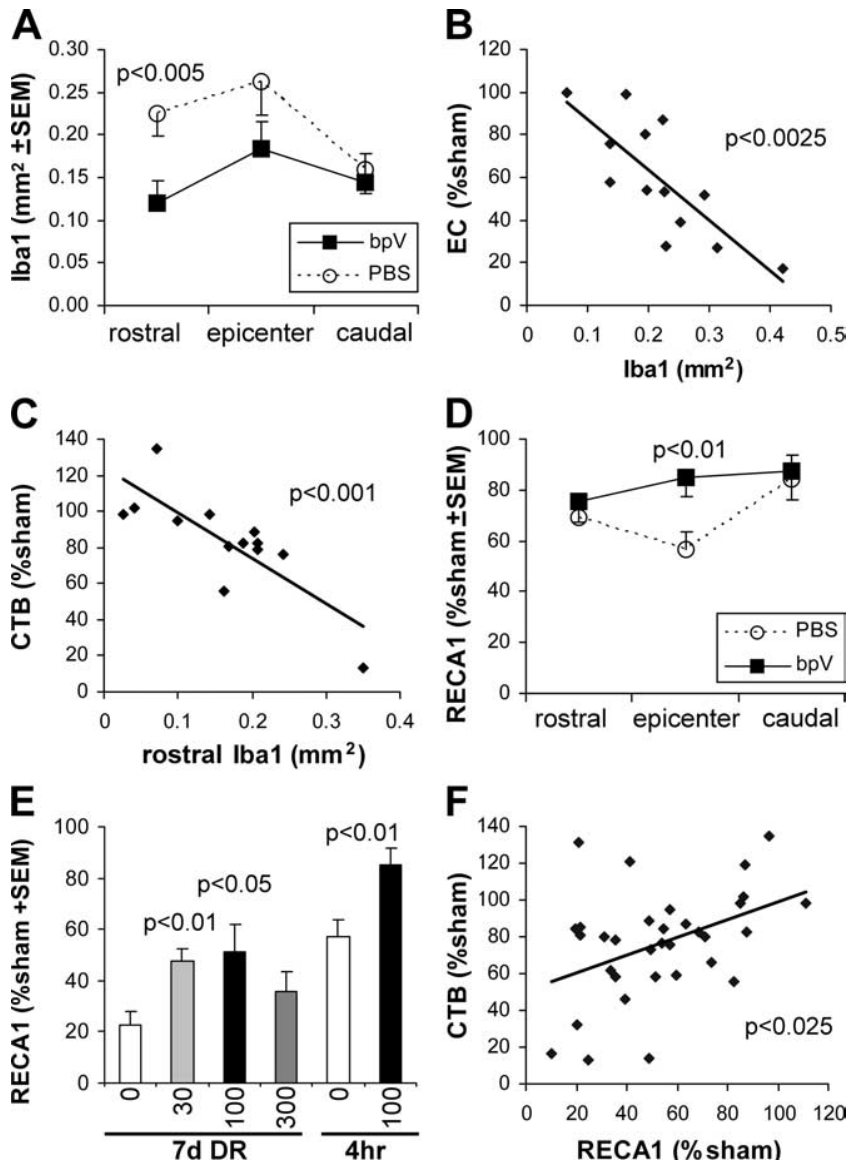

Figure 8. PTP inhibition may rescue axons by rescuing epicenter blood vessels. A, Quantification of the area of Iba1 as a measure of microglia/macrophage activation $7 \mathrm{~d}$ after spinal cord injury shows a reduction in the $b p V(p h e n)-$ treated group (bpV) only at $1 \mathrm{~mm}$ rostral to the injury epicenter. Only the rats in which the infusion was started $4 \mathrm{~h}$ after the injury were included. $\boldsymbol{B}$, EC staining measuring spared epicenter white matter shows a clear correlation between white matter loss and Iba1. C, The extent of loss of CTB-labeled projections only correlated with Iba 1 at $1 \mathrm{~mm}$ rostral to the epicenter. The epicenter and caudal levels are not shown. $\boldsymbol{D}$, Analyses of immunostaining for the endothelial cell marker RECA 1 in the dorsal column of the same sections show that bpV(phen) rescues blood vessels at the epicenter. $\boldsymbol{E}$, To increase the power of regression analyses, epicenter RECA1 was measured also in the rats from the dose-response (DR) study in which PBS or bpV(phen) infusions were started immediately after the injury and lasted for $7 \mathrm{~d}$. BpV(phen) increases the area when given at 30 or $100 \mu \mathrm{m}$ starting immediately after the injury. The $4 \mathrm{~h}$ delayed treatment groups in $\boldsymbol{D}$ is shown again for comparison. $\boldsymbol{F}$, Regression analysis for the combined values of all experimental groups from $\boldsymbol{E}$ shows a correlation between the area of dorsal column blood vessels (RECA1) and the extent of dorsal column axonal projections to the gracile nucleus (CTB).

the transcription factor Nrf2 by intraperitoneal injection of sulforaphane rescues endothelial cells after traumatic brain injury in rats and mice (Zhao et al., 2007). Our observations identify PTPs as novel targets to rescue endothelial cells after neurotrauma with potential implications for other disorders.

The neuroprotective mechanisms of $\mathrm{bpV}$ (phen) most likely involve PTPs, because bpV(phen) is a well characterized and specific PTP inhibitor (Posner et al., 1994; Fantus et al., 1995; Drake et al., 1996). bpV(phen) inhibits PTPs but not Ser/Thr phosphatases. Also, its insulin receptor kinase activation correlates with the tyrosine phosphorylation state of the receptor and its timedependent breakdown (Posner et al., 1994). bpV(phen) can inhibit the catalytic activity of purified yeast and mouse cdc25B PTP (Faure et al., 1995). Peroxovanadiums irreversibly inhibit PTPs by binding and oxidizing a critical cysteine in the catalytic domain (Posner et al., 1994; Bevan et al., 1995; Huyer et al.,
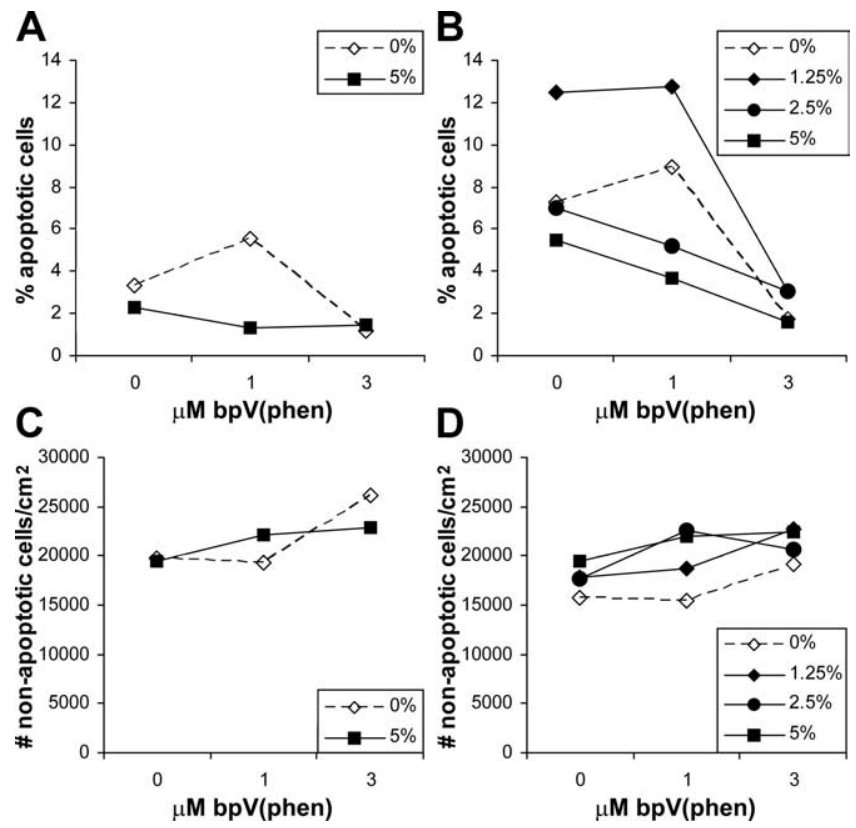

Figure 9. PTP inhibition rescues serum-deprived endothelial cells in vitro. $A$, Purified human aorta endothelial cells cultured for $6 \mathrm{~h}$ under serum-deprived conditions ( 0 or $5 \%$ serum instead of 10 $20 \%$ ) undergo apoptosis without addition of bpV(phen) (0). With $3 \mu \mathrm{m} \mathrm{bpV(phen),} \mathrm{fewer} \mathrm{cells} \mathrm{have}$ apoptotic nuclei. $\boldsymbol{B}$, After $18 \mathrm{~h}$ of culturing with various degrees of serum deprivation $(0,1.25,2.5$, and $5 \%$ serum), more endothelial cells undergo apoptosis without bpV(phen), but addition of $3 \mu \mathrm{m} \mathrm{bpV-}$ (phen) during that time rescues the cells. The $1 \mu \mathrm{m} \mathrm{bpV(phen)} \mathrm{treatment} \mathrm{only} \mathrm{reduces} \mathrm{endothelial}$ apoptosis in the 2.5 and $5 \%$ serum groups. These data suggest that bpV(phen) can directly rescue endothelial cells in vitro, as it may do in vivo after spinal cord injury.

1997). Moreover, bpV(phen)-induced protein tyrosine phosphorylation, and extracellular signal-regulated kinase (ERK) activation is reduced by antioxidants in cell lines (Krejsa et al., 1997). This raises the possibility that $\mathrm{bpV}(\mathrm{phen})$, like other metal-containing compounds, might oxidize proteins other than PTPs. However, bpV(phen) does not cause oxidative damage to DNA in C6 cells (Faure et al., 1995), does not change the glutathione concentration in rat cardiomyocytes ( $\mathrm{Li}$ et al., 2003), and does not cause death of $\mathrm{H}_{2} \mathrm{O}_{2}$-susceptible Madin-Darby canine kidney cells (Capella et al., 2007).

PTPs are a class of signaling proteins that can dephosphorylate tyrosine kinases (Johnson and Van Vactor, 2003; Paul and Lombroso, 2003; Alonso et al., 2004), suggesting that the protective mechanisms might include enhancement of intracellular tyrosine kinases signaling. The kinases involved in the rescue effects after spinal cord injury might include neurotrophic receptors (Airaksinen and Saarma, 2002; Huang and Reichardt, 2003), because $\mathrm{bpV}$ (phen) has neurotrophic and intracellular signaling effects similar to BDNF and neurotrophin-4 (Yang et al., 2007). We have shown that local injection of BDNF reduces degenerative changes in transected dorsal column sensory axons in rats (Sayer et al., 2002). Others have shown that glial cell line-derived neurotrophic factor, which activates the tyrosine kinase receptor Ret and ERK signaling (Trupp et al., 1999), can reduce axon and white matter loss after spinal cord injury (Iannotti et al., 2004). bpV(phen) is known to enhance ERK signaling in several systems (Sekar et al., 1996; Band et al., 1997; Ruff et al., 1997; Cerovac et al., 1999; Rumora et al., 2004; Blanchette et al., 2007). Peroxovandiums seem to be broad-spectrum PTP inhibitors, enhancing tyrosine phosphorylation of multiple proteins in multiple systems (Sekar et al., 1996; Ruff et al., 1997). It is therefore somewhat surprising that bpV(phen) can have neuroprotective effects without disrupting cellular functions, 
even when given over extended treatment periods up to 4 weeks. Conversely, bpV(phen) appears to be somewhat selective. Its insulinomimetic actions in vivo are limited to fewer organs than those of the related dipotassium bisperexo (picolinato) oxovanadate (V) [bpV(pic)] (Bevan et al., 1995). bpV(phen) activates AP1 in macrophages, whereas bpV(pic) does not (Blanchette et al., 2007). Moreover, $\mathrm{bpV}$ (phen) has differential effects on intracellular signaling pathways, stimulating survival-promoting ERK but not c-Jun N-terminal protein kinase, STAT1a, or nuclear factor $\kappa$ B (Rumora et al., 2004; Blanchette et al., 2007). Thus, it is possible that $\mathrm{bpV}$ (phen) primarily enhances function of proteins involved in axonal, oligodendrocyte, and endothelial survival and/or primarily reduces activity of PTPs involved in degeneration. It remains to be determined which PTPs are the major players in axonal, myelin, and endothelial survival and function, information that could lead to the development and testing of more selective inhibitors. Whether inhibitors selective for one or a few PTPs would lead to better neuroprotection after neurotrauma is not certain because broad-spectrum inhibitors such as bpV(phen) might affect multiple neurotrophic and growth factor receptor signaling pathways, thereby potentially providing synergy.

\section{References}

Airaksinen MS, Saarma M (2002) The GDNF family: signalling, biological functions and therapeutic value. Nat Rev Neurosci 3:383-394.

Alonso A, Sasin J, Bottini N, Friedberg I, Friedberg I, Osterman A, Godzik A, Hunter T, Dixon J, Mustelin T (2004) Protein tyrosine phosphatases in the human genome. Cell 117:699-711.

Baker KA, Hagg T (2005) An adult rat spinal cord contusion model of sensory axon degeneration: the estrus cycle or a preconditioning lesion do not affect outcome. J Neurotrauma 22:415-428.

Baker KA, Nakashima S, Hagg T (2007) Dorsal column sensory axons lack TrkC and are not rescued by local neurotrophin-3 infusions following spinal cord contusion in adult rats. Exp Neurol 205:82-91.

Ballermann M, McKenna J, Whishaw IQ (2001) A grasp-related deficit in tactile discrimination following dorsal column lesion in the rat. Brain Res Bull 54:237-242.

Band CJ, Posner BI, Dumas V, Contreres JO (1997) Early signaling events triggered by peroxovanadium $[\mathrm{bpV}(\mathrm{phen})]$ are insulin receptor kinase (IRK)-dependent: specificity of inhibition of IRK-associated protein tyrosine phosphatase(s) by bpV(phen). Mol Endocrinol 11:1899-1910.

Bevan AP, Drake PG, Yale JF, Shaver A, Posner BI (1995) Peroxovanadium compounds: biological actions and mechanism of insulin-mimesis. Mol Cell Biochem 153:49-58.

Blanchette J, Pouliot P, Olivier M (2007) Role of protein tyrosine phosphatases in the regulation of interferon- $\gamma$-induced macrophage nitric oxide generation: implication of ERK pathway and AP-1 activation. J Leukoc Biol 81:835-844.

Bowes M, Tuszynski MH, Conner J, Zivin JA (2000) Continuous intrathecal fluid infusions elevate nerve growth factor levels and prevent functional deficits after spinal cord ischemia. Brain Res 883:178-183.

Brodal P (1992) The central nervous system: structure and function. New York: Oxford UP.

Capella MA, Capella LS, Valente RC, Gefé M, Lopes AG (2007) Vanadateinduced cell death is dissociated from $\mathrm{H}_{2} \mathrm{O}_{2}$ generation. Cell Biol Toxicol 23:413-420.

Casella GT, Bunge MB, Wood PM (2006) Endothelial cell loss is not a major cause of neuronal and glial cell death following contusion injury of the spinal cord. Exp Neurol 202:8-20.

Cerovac Z, Ban J, Morinville A, Yaccato K, Shaver A, Maysinger D (1999) Activation of MAPK by potassium bisperoxo(1,10-phenanthroline) oxovanadate (V). Neurochem Int 34:337-344.

Cliffer KD, Giesler GJ Jr (1989) Postsynaptic dorsal column pathway of the rat. III. Distribution of ascending afferent fibers. J Neurosci 9:3146-3168.

Drake PG, Bevan AP, Burgess JW, Bergeron JJ, Posner BI (1996) A role for tyrosine phosphorylation in both activation and inhibition of the insulin receptor tyrosine kinase in vivo. Endocrinology 137:4960-4968.

Fantus IG, Deragon G, Lai R, Tang S (1995) Modulation of insulin action by vanadate: evidence of a role for phosphotyrosine phosphatase activity to alter cellular signaling. Mol Cell Biochem 153:103-112.

Faure R, Vincent M, Dufour M, Shaver A, Posner BI (1995) Arrest at the G2/M transition of the cell cycle by protein-tyrosine phosphatase inhibition: studies on a neuronal and a glial cell line. J Cell Biochem 59:389-401.

Ganchrow D, Margolin JK, Bernstein JJ (1980) Component analysis of hind limb behavioral alterations after damage to the rat dorsal funiculus. Exp Neurol 70:339-355.

Gris D, Marsh DR, Oatway MA, Chen Y, Hamilton EF, Dekaban GA, Weaver LC (2004) Transient blockade of the CD11d/CD18 integrin reduces secondary damage after spinal cord injury, improving sensory, autonomic, and motor function. J Neurosci 24:4043-4051.

Hagg T, Oudega M (2006) Degenerative and spontaneous regenerative processes after spinal cord injury. J Neurotrauma 23:264-280.

Hains BC, Saab CY, Lo AC, Waxman SG (2004) Sodium channel blockade with phenytoin protects spinal cord axons, enhances axonal conduction, and improves functional motor recovery after contusion SCI. Exp Neurol 188:365-377.

Huang EJ, Reichardt LF (2003) Trk receptors: roles in neuronal signal transduction. Annu Rev Biochem 72:609-642.

Hubscher CH, Johnson RD (2006) Chronic spinal cord injury induced changes in the responses of thalamic neurons. Exp Neurol 197:177-188.

Huyer G, Liu S, Kelly J, Moffat J, Payette P, Kennedy B, Tsaprailis G, Gresser MJ, Ramachandran C (1997) Mechanism of inhibition of proteintyrosine phosphatases by vanadate and pervanadate. J Biol Chem 272:843-851.

Iannotti C, Ping Zhang Y, Shields CB, Han Y, Burke DA, Xu XM (2004) A neuroprotective role of glial cell line-derived neurotrophic factor following moderate spinal cord contusion injury. Exp Neurol 189:317-332.

Johnson KG, Van Vactor D (2003) Receptor protein tyrosine phosphatases in nervous system development. Physiol Rev 83:1-24.

Krejsa CM, Nadler SG, Esselstyn JM, Kavanagh TJ, Ledbetter JA, Schieven GL (1997) Role of oxidative stress in the action of vanadium phosphotyrosine phosphatase inhibitors. Redox independent activation of NFkappaB. J Biol Chem 272:11541-11549.

Li S, Li X, Rozanski GJ (2003) Regulation of glutathione in cardiac myocytes. J Mol Cell Cardiol 35:1145-1152.

Liverman CT, Altevogt BM, Joy JE, Johnson RT,eds (2005) Spinal cord injury: progress, promise, and priorities. Washington, DC: National Academies.

Loy DN, Crawford CH, Darnall JB, Burke DA, Onifer SM, Whittemore SR (2002) Temporal progression of angiogenesis and basal lamina deposition after contusive spinal cord injury in the adult rat. J Comp Neurol 445:308-324.

Lu X, Maysinger D, Hagg T (2002) Tyrosine phosphatase inhibition enhances neurotrophin potency and rescues nigrostriatal neurons in adult rats. Exp Neurol 178:259-267.

McKenna JE, Whishaw IQ (1999) Complete compensation in skilled reaching success with associated impairments in limb synergies, after dorsal column lesion in the rat. J Neurosci 19:1885-1894.

Paul S, Lombroso PJ (2003) Receptor and nonreceptor protein tyrosine phosphatases in the nervous system. Cell Mol Life Sci 60:2465-2482.

Popovich PG, Guan Z, Wei P, Huitinga I, van RooijenN, Stokes BT (1999) Depletion of hematogenous macrophages promotes partial hindlimb recovery and neuroanatomical repair after experimental spinal cord injury. Exp Neurol 158:351-365.

Popovich PG, Guan Z, McGaughy V, Fisher L, Hickey WF, Basso DM (2002) The neuropathological and behavioral consequences of intraspinal microglial/macrophage activation. J Neuropathol Exp Neurol 61:623-633.

Posner BI, Faure R, Burgess JW, Bevan AP, Lachance D, Zhang-Sun G, Fantus IG, Ng JB, Hall DA, Lum BS (1994) Peroxovanadium compounds. A new class of potent phosphotyrosine phosphatase inhibitors which are insulin mimetics. J Biol Chem 269:4596-4604.

Rabchevsky AG, Fugaccia I, Sullivan PG, Scheff SW (2001) Cyclosporin A treatment following spinal cord injury to the rat: behavioral effects and stereological assessment of tissue sparing. J Neurotrauma 18:513-522.

Ruff SJ, Chen K, Cohen S (1997) Peroxovanadate induces tyrosine phosphorylation of multiple signaling proteins in mouse liver and kidney. J Biol Chem 272:1263-1267.

Rumora L, Hadzija M, Maysinger D, Zanić-GrubisićT (2004) Positive regulation of ERK activation and MKP-1 expression by peroxovanadium complex bpV (phen). Cell Biol Toxicol 20:293-301.

Sayer FT, Oudega M, Hagg T (2002) Neurotrophins reduce degeneration of 
injured ascending sensory and corticospinal motor axons in adult rat spinal cord. Exp Neurol 175:282-296.

Schucht P, Raineteau O, Schwab ME, Fouad K (2002) Anatomical correlates of locomotor recovery following dorsal and ventral lesions of the rat spinal cord. Exp Neurol 176:143-153.

Schwartz G, Fehlings MG (2001) Evaluation of the neuroprotective effects of sodium channel blockers after spinal cord injury: improved behavioral and neuroanatomical recovery with riluzole. J Neurosurg 94:245-256.

Sekar N, Li J, Shechter Y (1996) Vanadium salts as insulin substitutes: mechanisms of action, a scientific and therapeutic tool in diabetes mellitus research. Crit Rev Biochem Mol Biol 31:339-359.

Smith KJ, Bennett BJ (1987) Topographic and quantitative description of rat dorsal column fibres arising from the lumbar dorsal roots. J Anat 153:203-215.

Teng YD, Choi H, Onario RC, Zhu S, Desilets FC, Lan S, Woodard EJ, Snyder EY, Eichler ME, Friedlander RM (2004) Minocycline inhibits contusion-triggered mitochondrial cytochrome $\mathrm{c}$ release and mitigates functional deficits after spinal cord injury. Proc Natl Acad Sci U S A 101:3071-3076.

Trupp M, Scott R, Whittemore SR, Ibáñez CF (1999) Ret-dependent and -independent mechanisms of glial cell line-derived neurotrophic factor signaling in neuronal cells. J Biol Chem 274:20885-20894.

Webb AA, Muir GD (2003) Unilateral dorsal column and rubrospinal tract injuries affect overground locomotion in the unrestrained rat. Eur J Neurosci 18:412-422.

Yang P, Dankowski A, Hagg T (2007) Protein tyrosine phosphatase inhibition reduces degeneration of dopaminergic substantia nigra neurons and projections in 6-OHDA treated adult rats. Eur J Neurosci 25:1332-1340.

Zhang YP, Iannotti C, Shields LB, Han Y, Burke DA, Xu XM, Shields CB (2004) Dural closure, cord approximation, and clot removal: enhancement of tissue sparing in a novel laceration spinal cord injury model. J Neurosurg 100:343-352.

Zhang YP, Shields LB, Zhang Y, Pei J, Xu XM, Hoskins R, Cai J, Qiu MS, Magnuson DS, Burke DA, Shields CB (2007) Use of magnetic stimulation to elicit motor evoked potentials, somatosensory evoked potentials, and H-reflexes in non-sedated rodents. J Neurosci Methods 165:9-17.

Zhang YP, Burke DA, Shields LB, Chekmenev SY, Dincman T, Zhang Y, Zheng Y, Burke DA, Smith RR, Benton RL, DeVries WH, Hu X, Magnuson DSK, Whittemore SR, Shields CB (2008) Combined assessment to discriminate small functional differences following spinal cord contusion based on precise vertebral stabilization and tissue displacement. J Neurotrauma, in press.

Zhao J, Moore AN, Redell JB, Dash PK (2007) Enhancing expression of Nrf2-driven genes protects the blood brain barrier after brain injury. J Neurosci 27:10240-10248. 